International Journal of Pure and Applied Mathematics

Volume 107 No. 1 2016, 179-186

ISSN: 1311-8080 (printed version); ISSN: 1314-3395 (on-line version)

url: http://www.ijpam.eu

doi: $10.12732 /$ ijpam.v107i1.14

\title{
APPLICATION OF CONDITIONAL GRADIENT METHOD TO A CORPORATE FINANCING PROBLEM
}

\author{
B. Barysbyek ${ }^{1}$, N. Tungalag ${ }^{2}$, R. Enkhbat ${ }^{3} \S$ \\ ${ }_{1,3}^{3}$ Institute of Mathematics \\ National University of Mongolia \\ Ulaanbaatar, MONGOLIA \\ ${ }^{2}$ Business School \\ National University of Mongolia
}

\begin{abstract}
The determination of optimal financing sources is crucial in efficient and profitable corporate affairs. In this paper, we consider a model, first proposed by Davis and Elzinga [3], which is one of the well known and pioneering optimal control models in deterministic financial modeling. We show that the problem is nonconvex optimal control problem and did attempt to improve a result obtained in [11] by applying the conditional gradient algorithm starting from different initial controls.
\end{abstract}

AMS Subject Classification: 49M, 49D

Key Words: Davis-Elzinga model, global solution, conditional gradient method, optimal control

\section{Introduction}

Financial modeling has experienced dramatic improvements since the beginning of the $20^{\text {th }}$ century. Especially stochastic financial modeling was developed significantly. In 1970 Davis [4] stated a deterministic model for optimal corporate finance in form of a next non-linear optimal control problem:

Received: January 21, 2016

Published: March 26, 2016

${ }^{\S}$ Correspondence author (c) 2016 Academic Publications, Ltd.

url: www.acadpubl.eu 


$$
\begin{gathered}
\max \left\{P(T) e^{-\rho T}+\int_{0}^{T} e^{-\rho t}\left[1-u_{r}(t)\right] r E(t) d t\right\} \\
\dot{P}(t)=c\left[\left\{1-u_{r}(t)\right\} r E(t)-\rho P(t)\right] \\
\dot{E}(t)=r E(t)\left[u_{r}(t)+u_{s}(t)\left\{1-\frac{E(t)}{(1-\delta) P(t)}\right\}\right] \\
u(t) \in U=\left\{u \in \mathbb{R}^{2} \mid u_{r}+u_{s} \leq k / r<1, u_{r} \geq 0, u_{s} \geq 0\right\}
\end{gathered}
$$

where $P(0)=P_{0}, E(0)=E_{0}$ and the terminal condition is given by planning horizon $T^{1}$.

Then in joint paper with Elzinga [3] Davis provided a possible analytical solution to his problem (1)-(4). In 2005 Chen and Sardar [11] suggested a computational method for solving Davis and Elzinga model and provided computer software $\mathrm{SCOM}^{2}$. However, regardless of the nonconvex structure ${ }^{3}$ of the problem, they applied Pontryagin's maximum principle to the problem finding a local solution.

In this paper we suggest the conditional gradient method [1] with appropriate algorithm for finding local optimums of the original problem.

\section{Conditional Gradient Method}

Let us rewrite state variables as $x_{1}(t)=P(t), x_{2}(t)=E(t)$ and restate the model as follows:

$$
\max \left\{x_{1}(T) e^{-\rho T}+\int_{0}^{T} e^{-\rho T}\left[1-u_{r}(t)\right] r x_{2}(t) d t\right\}
$$

\footnotetext{
${ }^{1} P(t)$ - market price of a share of stock, $E(t)$ - equity per share of outstanding common stock (net worth of utility divided by the number of shares outstanding), $u_{r}$ - retention rate which describes the fraction of earnings retained for increasing the capital assets, $u_{\mathrm{s}}$ stock financing rate concerning new money invested in the company, $\rho$ - market capitalization rate (or investor discount rate), $k$ - maximum investment rate, $r$ - rate of return to equity (maximum return allowed by government), $\delta$ - discount on share price resulting from flotation cost, $c$ - a positive constant denoting the responsiveness of the price to changes in earnings and dividends, $T$ - planning horizon of the optimal financing program.

${ }^{2}$ In 2001 Craven and Islam first developed this package and used for solving optimal control problems.

${ }^{3}$ In (3) right side of the differential equation has a state variable in quadratic form $\left(E^{2}(t)\right)$ which results in nonconvex form of the reachable set.
} 


$$
\begin{gathered}
\dot{x_{1}}(t)=c\left[\left\{1-u_{r}(t)\right\} r x_{2}(t)-\rho x_{1}(t)\right] \\
\dot{x_{2}}(t)=r x_{2}(t)\left[u_{r}(t)+u_{s}(t)\left\{1-\frac{x_{2}(t)}{(1-\delta) x_{1}(t)}\right\}\right] \\
x_{1}(0)=x_{1}^{0}, x_{2}(0)=x_{2}^{0} \\
u(t) \in U=\left\{u \in \mathbb{R}^{2} \mid u_{r}+u_{s} \leq k / r<1, u_{r} \geq 0, u_{s} \geq 0\right\}
\end{gathered}
$$

We introduce a new variable $x_{3}$ as follows:

$$
\begin{aligned}
& x_{3}(\tau)=\int_{0}^{\tau} e^{-\rho t}\left[1-u_{r}\right] r x_{2}(t) d t \\
& \dot{x_{3}}(t)=e^{-\rho t}\left[1-u_{r}\right] r x_{2}(t), \\
& x_{3}(0)=0 .
\end{aligned}
$$

Then we can restate (5)-(9) in a terminal functional form:

$$
\begin{gathered}
\min \left\{\varphi(x(T))=-x_{1}(T) e^{-\rho T}-x_{3}(T)\right\} \\
\dot{x_{1}}(t)=c\left[\left\{1-u_{r}(t)\right\} r x_{2}(t)-\rho x_{1}(t)\right] \\
\dot{x_{2}}(t)=r x_{2}(t)\left[u_{r}(t)+u_{s}(t)\left\{1-\frac{x_{2}(t)}{(1-\delta) x_{1}(t)}\right\}\right] \\
\dot{x_{3}}(t)=e^{-\rho t}\left[1-u_{r}\right] r x_{2}(t) \\
x_{1}(0)=x_{1}^{0}, x_{2}(0)=x_{2}^{0} \\
u(t) \in U=\left\{u \in \mathbb{R}^{2} \mid u_{r}+u_{s} \leq k / r<1, u_{r} \geq 0, u_{s} \geq 0\right\}
\end{gathered}
$$

Problem (10)-(15) is nonconvex optimal control problem, and therefore applying Pontryagin's maximum principle cannot always guarantee a global solution. As control constraint set $U$ is compact, we can use conditional gradient method in infinite dimensional space.

Let us construct Pontryagin's function as follows:

$$
\begin{gathered}
H(\Psi, x, u, t)=\Psi_{1}(t) c\left[\left(1-u_{r}\right) r x_{2}-\rho x_{1}\right]+\Psi_{2}(t) r x_{2}\left[u_{r}+u_{s}\left\{1-\frac{x_{2}}{(1-\delta) x_{1}}\right\}\right]+ \\
+\Psi_{3} e^{-\rho t}\left[1-u_{r}\right] r x_{2}
\end{gathered}
$$


where $\Psi_{1}, \Psi_{2}, \Psi_{3}$ are the solutions of the next system of adjoint differential equations:

$$
\left\{\begin{array}{l}
\dot{\Psi}_{1}(t)=-\frac{\partial H}{\partial x_{1}}=c \Psi_{1} \rho+\frac{x_{2}^{2} r \Psi_{2} u_{s}}{x_{1}^{2}(1-\delta)} \\
\dot{\Psi}_{2}(t)=-\frac{\partial H}{\partial x_{2}}=r\left(c \Psi_{1}+\Psi_{3} e^{-\rho t}\right)-r\left[\Psi_{2}-c \Psi_{1}-\Psi_{3} e^{-\rho t}\right] u_{r}- \\
-r \Psi_{2}\left\{1-\frac{x_{2}}{(1-\delta) x_{1}}\right\} u_{s}+\left\{\frac{\Psi_{2} r x_{2}}{(1-\delta) x_{1}}\right\} u_{s} \\
\dot{\Psi}_{3}(t)=-\frac{\partial H}{\partial x_{3}}=0 \\
\Psi_{1}(T)=-\frac{\partial \varphi}{\partial x_{1}}=e^{-\rho T} \\
\Psi_{2}(T)=0 \\
\Psi_{3}(T)=1
\end{array}\right.
$$

The objective functional of (5)-(9) is $J(u)=\varphi(x(T))$. It's gradient can be calculated as follows:

$$
\dot{J}(u)=-\frac{\partial H}{\partial u}=-\left\{\frac{\partial H}{\partial u_{r}}, \frac{\partial H}{\partial u_{s}}\right\},
$$

where,

$$
\left\{\begin{array}{l}
-\frac{\partial H}{\partial u_{\mathrm{r}}}=\Psi_{1} c r x_{2}-\Psi_{2} r x_{2}+\Psi_{3} e^{-\rho T} r x_{2} \\
-\frac{\partial H}{\partial u_{\mathrm{s}}}=-\left[\Psi_{2} r x_{2}\left(1-\frac{x_{2}}{(1-\delta) x_{1}}\right)\right]
\end{array}\right.
$$

Then (5)-(9) can be restated as follows:

$$
\begin{aligned}
& \min _{u \in U} J(u), U \subset H, \\
& J(u) \in C^{1}(H)
\end{aligned}
$$

where, $U$ is weak compact, $H$ - Hilbert space, $C^{1}(H)$ - space of functionals continuously differentiable on $H$.

\section{Computational Algorithm}

\section{Algorithm 1 (Conditional gradient)}

Step 1. Choose arbitrary initial control $u^{0}=\left(u_{r}^{0}, u_{s}^{0}\right) \in U$, set $u^{k}, k:=0$.

Step 2. Solve (6)-(7) for $u=u^{k}$ and compute values of $x^{k}(t)=\left(x_{1}^{k}(t), x_{2}^{k}(t)\right)$. Step 3. Solve system (17) and compute values of $\Psi^{k}(t)=\left(\Psi_{1}^{k}(t), \Psi_{2}^{k}(t), \Psi_{3}^{k}(t)\right)$. Step 4. Compute functional's gradient $\dot{J}\left(u^{k}\right)$ using (18):

$$
\dot{J}\left(u^{k}\right)=\left(-\frac{\partial H\left(\Psi^{k}, x^{k}, u^{k}, t\right)}{\partial u_{r}},-\frac{\partial H\left(\Psi^{k}, x^{k}, u^{k}, t\right)}{\partial u_{s}}\right),
$$


where $H\left(\Psi^{k}, x^{k}, u^{k}, t\right)$ is computed by (16).

Step 5. Solve next linear programming problem:

$$
\min _{u \in U}\left[\left\langle\dot{J}\left(u^{k}\right), u\right\rangle=-\frac{\partial H}{\partial u_{r}} u_{r}-\frac{\partial H}{\partial u_{s}} u_{s}\right] .
$$

Let $\bar{u}^{k}=\left(\bar{u}_{r}^{k}, \bar{u}_{s}^{k}\right)$ be a solution of the above problem, i.e.:

$$
\left\langle\dot{J}\left(u^{k}\right), u^{k}\right\rangle=\min _{u \in U}\left\langle\dot{J}\left(u^{k}\right), u\right\rangle, t \in[0, T] .
$$

Step 6. If $\left\langle\dot{J}\left(u^{k}\right), \overline{u^{k}}-u^{k}\right\rangle=0$ holds then $u^{k}$ is optimal. If $\left\langle\dot{J}\left(u^{k}\right), \overline{u^{k}}-u^{k}\right\rangle \neq 0$ holds proceed to Step 7 .

Step 7. Construct a segment $u^{k}(\alpha)$ :

$$
u^{k}(\alpha)=u^{k}+\alpha\left(\bar{u}^{k}-u^{k}\right), 0 \leq \alpha \leq 1 .
$$

Step 8. Choose $\alpha_{k}$ to hold next conditions:

$$
u^{k}\left(\alpha_{k}\right): \min _{0 \leq \alpha \leq 1} J\left(u^{k}(\alpha)\right)=J\left(u^{k}\left(\alpha_{k}\right)\right) .
$$

Step 9. Construct a control $u^{k+1}$ :

$$
u^{k+1}:=u^{k}\left(\alpha_{k}\right)=u^{k}+\alpha_{k}\left(\bar{u}^{k}-u^{k}\right) .
$$

Step 10. Set $k:=k+1$ and proceed to Step 2 .

Next theorem provides the convergence of the above algorithm:

Theorem 1. [20] Sequence $\left\{u^{k}\right\}$ generated by Algorithm 1 according to differential maximum principle of Pontryagin converges to stationary point of problem (5)-(9) as follows:

$$
\lim _{k \rightarrow \infty}\left\langle\dot{J}\left(u^{k}\right), \bar{u}^{k}-u^{k}\right\rangle=0
$$

\section{Numerical Experiments}

As mentioned above Ping Cheng and Islam Sardar [11] provided their numerical solution. They used next values of system parameters $\rho=0.1, k=0.15, r=$ $0.2, \delta=0.1, c=1, P(0)=0.5, E(0)=1$ and achieved maximum value of objective functional $f^{*}=2.04$ with terminal values of states $P(T)=x_{1}(T)=$ 
Table 1: $u_{r}(0)=0, u_{s}(0)=0$

\begin{tabular}{|c|c|c|c|}
\hline$t$ & $x_{1}(T)$ & $x_{2}(T)$ & $f^{*}$ \\
\hline 10 & 1.363990024 & 0.005175294 & $\mathbf{2 . 1 2 7 5 4}$ \\
20 & 1.360725818 & 0.002854255 & 2.12284 \\
30 & 1.359562271 & 0.002308791 & 2.12111 \\
50 & 1.358626698 & 0.001938102 & 2.12111 \\
70 & 1.358227107 & 0.001795339 & 2.12111 \\
100 & 1.357928621 & 0.001694181 & 2.11866 \\
\hline
\end{tabular}

Table 2: $u_{r}(0)=0.375, u_{s}(0)=0.375$

\begin{tabular}{|c|c|c|c|}
\hline$t$ & $x_{1}(T)$ & $x_{2}(T)$ & $f^{*}$ \\
\hline 10 & 1.353424465 & 0.00353208 & 2.11288 \\
20 & 1.355974687 & 0.00233097 & 2.11705 \\
30 & 1.356695453 & 0.002011626 & 2.11796 \\
50 & 1.357103472 & 0.001781852 & $\mathbf{2 . 1 1 8 2 6}$ \\
70 & 1.357210419 & 0.001689978 & 2.11823 \\
100 & 1.357257493 & 0.001623573 & 2.11813 \\
\hline
\end{tabular}

Table 3: $u_{r}(0)=0.75, u_{s}(0)=0$

\begin{tabular}{|c|c|c|c|}
\hline$t$ & $x_{1}(T)$ & $x_{2}(T)$ & $f^{*}$ \\
\hline 10 & 1.353424465 & 0.00353208 & 2.11288 \\
20 & 1.355974687 & 0.00233097 & 2.11705 \\
30 & 1.356695453 & 0.002011626 & 2.11796 \\
50 & 1.357103472 & 0.001781852 & $\mathbf{2 . 1 1 8 2 6}$ \\
70 & 1.357210419 & 0.001689978 & 2.11823 \\
100 & 1.357257493 & 0.001623573 & 2.11813 \\
\hline
\end{tabular}

1.99, $E(T)=x_{2}(T)=1.96$. To find the best solution of the problem, as $U$ is a triangular set, we chose 4 initial controls as follows: $u_{a}^{0}=\{0,0\}, u_{b}^{0}=$ $\{0.375,0.375\}, u_{c}^{0}=\{0.75,0\}, u_{d}^{0}=\{0,0.75\}$.

From this we can see that the solution we found is $f^{*}=2.12754>2.04$, which is better than the previous solutions proposed by Chen and Sardar. 
Table 4: $u_{r}(0)=0, u_{s}(0)=0.75$

\begin{tabular}{|c|c|c|c|}
\hline$t$ & $x_{1}(T)$ & $x_{2}(T)$ & $f^{*}$ \\
\hline 10 & 1.354151332 & 0.002330051 & $\mathbf{2 . 1 1 0 9 6}$ \\
20 & 1.352959975 & 0.001681294 & 2.10937 \\
30 & 1.352536452 & 0.001508424 & 2.10878 \\
50 & 1.352196923 & 0.001383136 & 2.1083 \\
70 & 1.35205227 & 0.001332709 & 2.1081 \\
100 & 1.35194438 & 0.001296109 & 2.10794 \\
\hline
\end{tabular}

\section{Conclusions}

In this paper we considered Davis-Elzinga optimal financing problem. We showed that previous numerical solution [11] is not a global solution, and proposed the conditional gradient algorithm in order to improve the existing solution.

\section{References}

[1] Bredies, K., Lorenz, D. A. and Maass P., (2007), A generalized conditional gradient method and its connection to an iterative shrinkage method, Computational Optimization and Applications, Volume 42, Issue 2, pp 173-193

[2] Craven, B. D., HAAS, K. De. and Wettenhall, J. M. (1998), Computing optimal control, Dynamics of Continious, Discrete and Impulsive Systems, pp. 601-615.

[3] Davis, B. E. and Elzinga, D. J. (1970), The solution of an optimal control problem in financial modeling, Operations research: the journal of the Operations Research Society of America, 19(6).

[4] Davis, B. E., Investment and Rate of Return for the Regulated Firm, The Bell Journal of Economics and Management Science, Volume 1, No. 2, 245-270, 1970.

[5] Elton, E., Gruber, M., Finance as a Dynamic Process, Prentice-Hall, New Jersey, 1975.

[6] Goh, G. J. and Teo, K. L. (1987), MISER, an Optimal Control Software, Department of Industrial and Systems Engineering, National University of Singapore.

[7] Krouse, C. G., Lee, W. Y., Optimal equity financing of the corporation, Journal of Financial and Quantitative Analysis, Voulme 8, 539-563, 1973.

[8] Lee, H. W. J., Teo, K. L., Rehbock, V. and Jennings, L. S. (1997), Control parameterization enhancing technique for time optimal control problems, Dynamic Systems and Applications, 6: 243-262.

[9] Modigliani, F. and Miller, M. H., The cost of capital, corporation finance, and the theory of investment, American Economic Review, Volume 48, No.3 :261-297, 1958. 
[10] Modigliani, F. and Miller, M. H., Corporation income taxes and the cost of capital, American Economic Review, Volume 53, No.3 :433-443, 1963.

[11] Ping Chen and Islam, S. M. N. (2005), Optimal Control Models in Finance: A New Computational Approach, Volume 95, Applied Optimization series, Springer.

[12] Ping Chen and Islam, S. M. N. (2008), Advances in Financial Planning and Forecasting, Volume 3, 37-66, Center for PBBEFR and Airiti Press Inc.

[13] Pontryagin, L. S., Boltyanskii, V. G., Gamkrelidze, R. V., Mischenko, E. F., The mathematical theory of optimal processes, "Nauka", Moscow, 1969.

[14] Sethi, P. S., Thompson, G. L., Optimal Control Theory: Applications to Management Science and Economics, Springer, 2000.

[15] Sethi, P.S., Optimal equity financing model of Krouse and Lee: corrections and extensions, Journal of Financial and Quantitative Analysis, Volume 13, 487-505, 1978.

[16] Jennings, L. S., Fisher, M. E., Teo, K. L. and Goh G. J. (1991), MISER3.0: Solving optimal control problems - an update, Advances in Engineering Software, 13.

[17] Tjatjushkin, A. I., Numerical methods for optimization of controlled systems, Stability and control: Theory and Applications, Volume 3, No. 2, 150-174, 2000.

[18] Tjatjushkin, A. I., Numerical solution of multiextreme optimal control problem, Russian Academy of Sciences, No.5, 59-67, 2004.

[19] Vasyliev, O. V., Methods of solving extreme problems: A course book, "Nauka", Moscow, 1981.

[20] Vasyliev, O. V., Numerical methods of solving extreme problems: A course book, "Nauka", Moscow, 1988. 